\title{
Perception of Risk for Lassa Fever among Residents of a Rural Community in Edo State, Nigeria
}

\author{
Alenoghena $\mathbf{I}^{1}$, Omuemu $\mathbf{V}^{2}$ \\ ${ }^{1}$ Department of Community Health, Ambrose Alli University, Ekpoma, Edo State, \\ Nigeria \\ ${ }^{2}$ Department of Community Health, University of Benin, Benin City, Edo State, Nigeria \\ Corresponding author: Innocent Alenoghena \\ E-mail:alendoc@yahoo.com \\ Phone: +2348035605691
}

\begin{abstract}
Background: The prevention and control of Lassa fever depends on the adoption of appropriate behavioural practices. The expected changes are best explained using the Health Belief Model. The study investigated respondents' perception of their risk for Lassa fever infection and its associated factors in Akhalowa community of Edo State.
\end{abstract}

Methods: This cross-sectional study was conducted among eligible heads of households using a structured interviewer-administered questionnaire. Data were analyzed using descriptive and inferential statistics on IBM SPSS version 22.0. A p-value $<0.05$ at 95\% confidence interval was considered statistically significant.

Results: The participants included 220 respondents with mean age (SD) of 37.9 (13.2) years. There were 127 (57.7\%) females and 143 (65.0\%) respondents had at least secondary education. One hundred and ninety one $(86.8 \%)$ of them were aware of Lassa fever, out of which $146(76.4 \%)$ had overall good perception of their risk for the disease and 144 (75.4\%) agreed that Lassa fever was a problem in the community. One hundred and seventy seven (92.7\%) agreed that complying with preventive measures would protect them against Lassa fever. Respondents' good knowledge of Lassa fever was the only significant predictor of good perception of risk for Lassa fever [Odds Ratio $=3.806$; $95 \mathrm{CI}=1.498-9.672, p=0.005]$.

Conclusion: The study revealed overall good perception of risk for Lassa fever among the respondents. It is therefore recommended that this is sustained through continuous risk communication messages on the prevention and control of Lassa fever to the people by the Edo State and local governments.

Keywords: Lassa fever, Riskperception, Edo State, Nigeria.

\section{Introduction}

Lassa Fever (LF) is an acute viral hemorrhagic disease which is caused by a single stranded RNA Lassa virus of the arenaviridae family. ${ }^{1}$ It is present in most parts of Nigeria and other West African countries like Sierra Leone, Guinea, Ghana, Mali and Liberia where it causes 3- 
5 million new infections and 5000-10,000 deaths yearly. ${ }^{2,3,4,5}$ The disease is extremely virulent and has a case fatality rate (CFR) of between $1-15 \%$. The CFR may be as high as $20 \%$ in hospitalized patients and $80 \%$ during the third trimester of pregnancy. ${ }^{6}$ The incidence of Lassa fever is usually highest during the dry season (December- April) but can also occur allyear-round without any predilection for dry season.

The primary mode of transmission of Lassa fever virus is from a rodent to human via the Mastomys natalensis rodent, which is the natural reservoir of the virus. ${ }^{8}$ However, human-to-human transmission also occurs through contact with body fluid of an infected person. ${ }^{6}$ Those infected with the disease commonly present with fever, general weakness, headache, sore throat, muscle pain, cough, chest pain, nausea, vomiting, diarrheoa, abdominal pain and bleeding from the orifices. ' Common complications of the disease include: deafness, spontaneous abortion, hypovolemic shock, electrolyte imbalance and renal failure.

The preventive practices for Lassa fever include hand washing, environmental hygiene, storage of foodstuff in rodent proof containers, maintenance of clean households, and early reporting of suspected cases. ' The prevention and control of LF also relies on promoting good community hygiene to discourage rodents from entering homes. ${ }^{11}$ These measures, which help to reduce the risk of the disease, are also very important in healthcare settings when caring for a patient infected with the virus. Ribavirin therapy is the drug of choice for the treatment of LF and when commenced before the $7^{\text {th }}$ day of illness, reduces fatalities from the disease. ${ }^{12}$ Currently, no vaccine is available for the prevention of the disease. . $^{8,9-12-14}$

Health education is a major ingredient of the primordial and primary levels of Lassa fever prevention, as it influences the level of awareness of the disease and its risk perception, and shapes health-related behaviour. ${ }^{15}$ The desired changes in the human behaviour are best explained with the use of the Health Belief Model (HBM). The HBM postulates that when an individual perceives that he or she is at risk of contracting a serious disease (threat), he or she will initiate a certain health behaviour to prevent it. ${ }^{15}$ It focuses on two aspects of individual's representation of health behaviour: threat perception and behaviour evaluation. The threat perception is further subdivided into perceived susceptibility to health problems and anticipated severity of the consequences of illness. Therefore, the identification of perceived risk to a disease becomes an extremely important step in the evaluation of the status of the individuals and the community in disease prevention and control. ${ }^{12,16}$

Eliciting the perception of households towards LF has become particularly important because of the repeated outbreaks of the disease in the northern and central senatorial districts of Edo State over the last decade. ${ }^{13}$ This study, therefore aimed to assess respondents' perception of risk for Lassa fever and its associated factors.

\section{Methods}

\section{Study area}

This was a cross-sectional study carried out in Akhulowa community in Etsako West Local Government Area (LGA) in the northern part of Edo State between August and October 2019. Etsako-west LGA has 12 wards and Akhulowa community is located in ward 11 (Uzairue South West ward). Akhulowa is a rural, predominantly 
agrarian community, which is made up of six quarters. Its predominant ethnic group and religion are Etsako and Islam respectively. It has one Primary Health Care (PHC) centre, one market, two primary and one secondary schools. Also, 'garri', a staple food made from cassava plant is produced in large quantities from this community and its environs. The production of garri within these communities is associated with certain unhealthy practices, like spreading it on the ground and preserving it poorly before consumption. Inhabitants of these communities also engage in seasonal bush burning, hunting and consumption of rats. ${ }^{17}$ Furthermore, during the outbreak of LF in Nigeria in 2019, there were 12 deaths and 871 confirmed cases of LF in Etsako West LGA between January and April. Akhulowa community and other communities within ward 11 recorded the highest number of cases and deaths from that disease outbreak. ${ }^{18}$

\section{Study population, sample size determination and sampling}

The study population comprised of heads of households or their representatives (permanent residents, $\geq 18$ years who consented for the study). A sample size of 220 was determined using the formula for estimating minimum sample size for descriptive studies $\left(\mathrm{n}=\mathrm{Z} \alpha^{2} \mathrm{pq} / \mathrm{d}^{2}\right),{ }^{19}$ and a proportion of respondents with perceived risk towards LF in an earlier study of $17.5 \%,{ }^{12} Z_{\alpha}$ of 1.96 at $95 \%$ confidence level and a precision of $5 \%$. A cluster sampling method was adopted to select participants: the community comprised of six quarters (or settlements) with each housing about 70-90 households. For the purpose of this survey, each quarter was regarded as a cluster. Four of the quarters were selected by simple random sampling method and all eligible heads of households who met the inclusion criteria were interviewed using a structured questionnaire.

The questionnaire was designed by the researchers using available related literature and included questions on respondents' socio-demographic characteristics, and knowledge and perception of risk for Lassa fever. The questions on knowledge covered the causative agent, reservoir of infection, disease transmission, symptoms, prevention and treatment of LF. The questions on perception of risk for Lassa fever were structured based on the construct of the Health Belief Model to cover perceived seriousness, susceptibility, benefits of taking action, barriers to taking action and cues to action.

\section{Data analysis}

Data analysis was carried out using the IBM SPSS version 22.0. Univariate analysis was done to assess distribution of the variables and ensure completeness of data while bivariate analysis was done to determine the association between respondents' socio-demographic variables and risk perception of Lassa fever using Chi square test. Binary logistic regression using the "enter approach" was done to identify the significant predictors of overall perception of LF risk. A p-value < 0.05 at $95 \%$ confidence interval (CI) was considered statistically significant. Respondents' perception of risk for Lassa fever was assessed using 9 questions on a 5-point Likert scale (Strongly Agree to Strongly Disagree). The most positive response to any of the questions was given a score of 5 while the most negative response to any of the questions was given a score of 1 with minimum and maximum obtainable scores of 9 and 45 respectively. The total score for each respondent was converted to percentage and classified as: poor perception of risk (less than 50\%) and 
good perception of risk ( $50 \%$ and above). Respondents' knowledge of Lassa fever was assessed using eight (8) questions with some having multiple responses. A score of 1 was awarded for any correct response while a score of 0 for any incorrect response with the maximum obtainable score being 18. The total score for each respondent was converted to percentage and classified as poor knowledge (less than $50 \%)$ and good knowledge (50\% and above).

\section{Ethical consideration}

Ethical approval (Ref No: ADM/E 22/A/VOL. VII/14830946) for the study was obtained from the Ethics and Research Committee of the University of Benin Teaching Hospital. Permission was obtained from the LGA authority and the Daudu of Akhulowa community before commencement of the study. Informed consent was obtained from the respondents before data was collected. All data was kept secured and available to only members of the research team.

\section{Results}

Two hundred and twenty respondents with mean age (SD) 37.9 (13.2) years participated in the study. A higher proportion; $137(62.3 \%)$ of them were aged less than 40 years and $127(57.7 \%)$ were females. Close to two-thirds; 143 $(65.0 \%)$ had at least secondary education, $128(58.2 \%)$ were employed and 118 $(53.6 \%)$ had been living in the community for more than 20 years. Table 1 .

One hundred and ninety one $(86.8 \%)$ of the respondents were aware of Lassa fever. Of these, 144 (75.4\%) agreed that LF was a problem in the community. Furthermore,
$176(92.1 \%)$ agreed that LF was a problem in Nigeria. A greater proportion of the respondents; $163(85.3 \%)$ agreed that LF was the cause of preventable deaths in Nigeria while only $28(14.7 \%)$ disagreed with it. Only $95(49.7 \%)$ of the respondents agreed that they were at risk of contracting LF. Up to 177 (92.7\%) of the respondents agreed that complying with preventive measures would protect them against LF. Also, $161(84.3 \%)$ respondents believed that they could protect themselves against LF and 179 (93.7\%) intend to adopt measures to protect themselves against LF. Table 2. Overall, $146(76.4 \%)$ of the respondents had good perception of the disease risk while 45 $(23.6 \%)$ had poor perception of the risk.

Respondents' level of education, religion and knowledge of LF were significantly associated with perception of risk of Lassa fever. One hundred and seven $(80.5 \%)$ of those with higher level of education had good perception of risk of Lassa fever compared to $39(67.2 \%)$ of those with lower level of education, [Odds Ratio=2.00; $95 \mathrm{CI}=1.00-4.00, \mathrm{p}=0.048]$. One hundred and thirty six $(81.0 \%)$ of those with good knowledge of Lassa fever had good perception of risk of Lassa fever compared to $10(43.5 \%)$ of those with poor knowledge of Lassa fever and this was statistically significant, [Odds Ratio $=5.53$; $95 \mathrm{CI}=2.01-15.31, \mathrm{p}<0.001]$. Table 3 .

Respondents' knowledge of LF was the only significant predictor of perception of risk of Lassa fever on binary logistic regression analysis. Respondents with good knowledge were 3.8 times more likely to have good perception of risk of LF than those with poor knowledge [Odds Ratio=3.806; 95 CI $=1.498-9.672$, $p=0.005]$.Table 4 . 
Table 1: Socio-demographic characteristics of respondents

\begin{tabular}{|c|c|c|}
\hline Variable & Frequency $(n=220)$ & Percent \\
\hline \multicolumn{3}{|l|}{ Age group (years) } \\
\hline$<40$ & 137 & 62.3 \\
\hline$=40$ & 83 & 37.7 \\
\hline Mean (SD) & $37.91 \pm 13.18$ & \\
\hline \multicolumn{3}{|l|}{ Sex } \\
\hline Male & 93 & 42.3 \\
\hline Female & 127 & 57.7 \\
\hline \multicolumn{3}{|l|}{ Religion } \\
\hline Christianity & 130 & 59.1 \\
\hline Islam & 89 & 40.5 \\
\hline ATR* & 1 & 0.4 \\
\hline \multicolumn{3}{|l|}{ Marital status } \\
\hline Married & 173 & 78.6 \\
\hline Not married & 47 & 21.4 \\
\hline \multicolumn{3}{|l|}{ Level of education } \\
\hline No formal education & 28 & 12.7 \\
\hline Primary & 49 & 22.3 \\
\hline Secondary & 104 & 47.3 \\
\hline Tertiary & 39 & 17.7 \\
\hline \multicolumn{3}{|l|}{ Ethnicity } \\
\hline Etsako & 185 & 84.1 \\
\hline Others & 35 & 15.9 \\
\hline \multicolumn{3}{|l|}{ Employment status } \\
\hline Employed & 128 & 58.2 \\
\hline Not employed & 92 & 41.8 \\
\hline \multicolumn{3}{|c|}{ Monthly HH+ income ( } \\
\hline$<30,000$ & 102 & 46.4 \\
\hline$=30,000$ & 118 & 53.6 \\
\hline Mean (SD) & $49,895.45 \pm 6,666.34$ & \\
\hline \multicolumn{3}{|l|}{ Length of stay (years) } \\
\hline$<10$ & 60 & 27.3 \\
\hline $10-19$ & 42 & 19.1 \\
\hline$=20$ & 118 & 53.6 \\
\hline
\end{tabular}

* ATR=African Traditional Religion, $+\mathrm{HH}=$ Household 
Table 2: Respondents' perception of risk of Lassa fever

\begin{tabular}{lrc}
\hline Variable & $\begin{array}{c}\text { Perception of risk of Lassa fever } \\
\text { Agree } \\
\text { n (\%) }\end{array}$ & $\begin{array}{c}\text { Disagree } \\
\text { n (\%) }\end{array}$ \\
\hline Lassa fever is a problem in my community & $144(75.4)$ & $47(24.6)$ \\
Lassa fever is a problem in Nigeria & $176(92.1)$ & $15(7.9)$ \\
Lassa fever is a serious health problem & $177(92.7)$ & $14(7.3)$ \\
Lassa fever is a cause of preventable death in Nigeria & $163(85.3)$ & $28(14.7)$ \\
Consider myself at risk of contracting Lassa fever & $95(49.7)$ & $96(50.3)$ \\
It bothers me that I may get Lassa fever & $83(43.5)$ & $108(56.5)$ \\
Complying with preventive measures will protect me & $177(92.7)$ & $14(7.3)$ \\
I have the ability to protect myself & $161(84.3)$ & $30(15.7)$ \\
I intend to protect myself from infection & $179(93.7)$ & $12(6.3)$ \\
\hline $\mathrm{n}=191$ & &
\end{tabular}

Table 3: Association between respondents' socio-demographic characteristics and overall perception of risk of Lassa fever

\begin{tabular}{|c|c|c|c|c|}
\hline \multirow[b]{2}{*}{ Variables } & \multicolumn{2}{|c|}{ Overall risk perception } & \multirow[b]{2}{*}{$\begin{array}{l}\text { Test statistics/ } \\
\text { p-value }\end{array}$} & \multirow[b]{2}{*}{$\begin{array}{l}\text { Odd Ratio } \\
95 \text { CI }\end{array}$} \\
\hline & $\begin{array}{l}\text { Good n=146) } \\
n(\%)\end{array}$ & $\begin{array}{l}\text { Poor }(n=45) \\
n(\%)\end{array}$ & & \\
\hline \multicolumn{5}{|l|}{ Age group (years) } \\
\hline$<40$ & $91(72.8)$ & $34(27.2)$ & $\chi^{2}=2.661$ & $0.54(0.23-1.19)$ \\
\hline$=40$ & $55(83.3)$ & $11(16.7)$ & 0.103 & \\
\hline \multicolumn{5}{|l|}{ Sex } \\
\hline Male & $57(75.0)$ & $19(25.0)$ & $\chi^{2}=0.145$ & $0.88(0.42-1.84)$ \\
\hline Female & $89(77.4)$ & $26(22.6)$ & 0.703 & \\
\hline \multicolumn{5}{|l|}{ Religion } \\
\hline Christian & $96(82.8)$ & $20(17.2)$ & $\chi^{2}=6.549$ & $2.40(1.15-5.03)$ \\
\hline Islam & $50(66.7)$ & $25(33.3)$ & 0.010 & \\
\hline \multicolumn{5}{|l|}{ Level of Education } \\
\hline Secondary/Tertiary & $107(80.5)$ & $26(19.5)$ & $\chi^{2}=3.913$ & \\
\hline NFE/Primary & $39(67.2)$ & $19(32.8)$ & 0.048 & $2.00(1.00-4.00)$ \\
\hline \multicolumn{5}{|l|}{ Employment status } \\
\hline Employed & $89(77.4)$ & $26(22.6)$ & $\chi^{2}=0.145$ & $1.14(0.54-2.37)$ \\
\hline Not employed & $57(75.0)$ & $19(25.0)$ & 0.703 & \\
\hline \multicolumn{5}{|l|}{ HH income ( $\mathrm{N}$ ) } \\
\hline$<30,000$ & $73(73.7)$ & $26(26.3)$ & $\chi^{2}=0.833$ & $0.73(0.35-1.51)$ \\
\hline$=30,000$ & $73(79.3)$ & $19(20.7)$ & 0.361 & \\
\hline \multicolumn{5}{|c|}{ Length of stay (years) } \\
\hline$<10$ & $46(85.2)$ & $8(14.8)$ & $\chi^{2}=3.197$ & $2.13(0.88-5.70)$ \\
\hline$=10$ & $100(73.0)$ & $37(27.0)$ & 0.074 & \\
\hline \multicolumn{5}{|l|}{ Knowledge of LF } \\
\hline Good & $136(81.0)$ & $32(19.0)$ & $\chi^{2}=15.775$ & $5.53(2.01-15.31)$ \\
\hline Poor & $10(43.5)$ & $13(56.5)$ & $<0.001$ & \\
\hline
\end{tabular}

$\mathrm{CI}=$ Confidence Interval 
Table 4: Predictors of overall perception of Lassa fever among respondents

\begin{tabular}{|c|c|c|c|c|}
\hline \multirow[t]{2}{*}{ Variable } & \multirow[t]{2}{*}{ p-value } & \multirow[t]{2}{*}{ Odds Ratio } & \multicolumn{2}{|c|}{$95 \% \mathrm{CI}$} \\
\hline & & & Lower & Upper \\
\hline \multicolumn{5}{|l|}{ Age group (years) } \\
\hline $\begin{array}{l}<40 \\
=40^{*}\end{array}$ & 0.423 & $\begin{array}{l}1.051 \\
1\end{array}$ & 0.979 & 1.051 \\
\hline \multicolumn{5}{|l|}{ Sex } \\
\hline Male & 0.415 & 1.360 & 0.649 & 2.850 \\
\hline Female* & & 1 & & \\
\hline \multicolumn{5}{|l|}{ Religion } \\
\hline Christian & 0.282 & 1.493 & 0.719 & 3.098 \\
\hline Islam* & & 1 & & \\
\hline \multicolumn{5}{|l|}{ Level of education } \\
\hline Secondary/Tertiary & 0.576 & 0.793 & 0.353 & 1.786 \\
\hline $\begin{array}{l}\text { NFE/Primary* } \\
\text { Employment status }\end{array}$ & \multicolumn{4}{|c|}{ Employment status } \\
\hline Employed & 0.515 & 1.125 & 0.790 & 1.602 \\
\hline Not employed & & 1 & & \\
\hline \multicolumn{5}{|l|}{ Household income (?) } \\
\hline$=30,000^{*}$ & 0.305 & 0.623 & 0.564 & 1.000 \\
\hline Length of stay (years) & & & & \\
\hline$<10$ & 0.790 & 0.997 & 0.971 & 1.022 \\
\hline$\geq 10^{*}$ & & 1 & & \\
\hline \multicolumn{5}{|l|}{ Knowledge LF } \\
\hline Good & 0.005 & 3.806 & 1.498 & 9.672 \\
\hline Poor* & & & & \\
\hline
\end{tabular}

*Reference category, $\mathrm{R}^{2}=22.7 \%-34.1 \% \quad \mathrm{CI}=$ Confidence Interval

\section{Discussion}

Overall, more than three quarter of the respondents had a good perception of risk for LF disease. This may be related to the respondents' educational status, as education has been reported to be a favourable factor in determining disease knowledge. ${ }^{19}$ Almost two third of the participants had at least secondary education, a finding which is higher than the national average of $56 \%{ }^{19}$ Indeed, this implies that most people in this community can access health information through most channels of health communication and adopt relevant behavioral changes for disease prevention and control. The overall perception of risk is made up of the respondents' susceptibility to LF, their perceptions towards the severity of the disease and the benefits of preventive measures for the disease. ${ }^{19}$ In terms of respondents' perception towards the severity of Lassa fever, majority of the participants perceived that the disease is a serious health problem in the community. This finding reflects the degree of understanding of the nature of the disease by the respondents and their willingness to accept and inculcate preventive measures, 12 thereby reducing exposure to the infection and the resultant morbidity, prolonged hospitalization, loss of work, economic challenges and stigmatization in the society. In order to achieve improved awareness of diseases of public health importance and community participation, 
the Nigerian Government in collaboration with the World Health Organization established the Village Development Committees (VDCs) and Ward Development Health Committees (WDCs) across all wards in the country. ${ }^{20}$ These health committees, which have been reported to be fully functional in the study community and its environs, operate at the village or ward level and help to educate members of these communities on the required preventive and control measures for prevailing diseases. ${ }^{10}$

The finding from this study concerning the perceived severity of LF is slightly at variance with previous reports from Nigeria in which $19.6 \%$ and $85.3 \%$ of the respondents stated that LF was a serious problem. ${ }^{12,21}$ As regards susceptibility to LF, half of the respondents perceived that they were not at risk of contracting the disease. This is a cause for concern because it means these respondents are unlikely to observe the relevant preventive measures against the disease. This finding was incongruent with an earlier observation in Nigeria, where $22.7 \%$ and $60.7 \%$ of respondents perceived that they were probably and certainly susceptible to LF respectively. ${ }^{12}$ In terms of the possible benefits of preventive measures, majority of the respondents agreed that complying with preventive measures would protect them against LF. This particularly impressive observation implies that most of the participants were willing to adopt preventive measures to contain the continuous spread of the disease. It also means that repeated risk communication messages would yield the desired results. However, this finding was higher than a previous observation from Nigeria, ${ }^{12}$ in which fewer participants stated that they were convinced that preventive measures were very beneficial towards containing the disease. The higher value obtained from this study may not be unrelated to the educational status of the respondents and the benefits of risk communication messages from previous outbreaks of the disease.

Though respondents' higher level of education was associated with good perception of risk for LF, it was not a significant predictor. Moreover, this observation gives credence to the importance of the educational status of individuals in having knowledge of common diseases in our society. However, this finding was at variance with a previous report from Nigeria. ${ }^{12}$ Having good knowledge of LF was the only significant predictor of good perception of risk of the disease. The finding is in keeping with the results from a population survey carried out in south eastern Nigeria, where good knowledge was reported to be significantly associated with perceived susceptibility to LF disease. ${ }^{12}$ However, this was at variance with the results from a previous cross sectional study carried out among inhabitants of a forest region in Guinea, in which only factors related to receiving an injection and prolonged physical contacts with somebody with LF were associated with increased risk for the disease. ${ }^{8}$ Nonetheless, this finding may also not be unrelated to the significance of education in the improvement of man in the areas of disease prevention and control. ${ }^{22}$ It therefore means that when the individuals are empowered with the knowledge of a disease, they will most likely develop a better perception of risk towards the disease. Improved knowledge for diseases can most commonly be achieved through repeated health education and risk communication messages within our environment. ${ }^{23}$

\section{Conclusion}

More than three quarter of the participants 
of this study demonstrated an overall good perception of risk for LF, which is suggestive of an impressive level of knowledge and understanding of LF among them. Respondents' good knowledge of LF was the only significant predictor of good perception of risk of the disease. It is therefore recommended that health education and risk communication messages on the prevention and control of LF should be intensified by the Edo State Government and LGA health authorities.

\section{References}

1. Bowen MD, Robin PE, Ksiazek TG et al. Genetic Diversity among Lassa virus strains. J Virol 2000; 74: 69927004.

2. Buchmeier M.J. Arenaviridae: the viruses and their replication. Fields virology 2007: 1792-827.

3. Olugasa BO, Odigie EA, Lawani M, Ojo JF. Development of a time-trend model for analyzing and predicting case pattern of Lassa fever epidemics in Liberia. Ann Afr Med 2015; 14(2): 89-96.

4. Nigeria Centre for Disease Control. Lassa fever Situation Report. Abuja, $\begin{array}{llll}2 & 0 & 2 & 0\end{array}$; https://ncdc.gov.ng/diseases/sitreps/? cat $=57$ name $=$ An + update + of + Lassa + fever+outbreak + in + Nigeria.

5. Rine CR, Gyar SD. Knowledge, attitude and practice of Lassa fever in and around Lafia, Central Nigeria. IJPHER 2016; 2(1): 014-9.

6. Wold Health Organization. Lassa Fever. Geneva: WHO 2017 ; https://www.who.int/en/newsroom/fact-sheet/detail/lassa-fever. Accessed 2021 May 10

7. World Health Organization. Fact Sheet on Lassa Fever. In: Regional Office for Africa, WHO Geneva; 2019 https://www.who.int/healthtopics/lassa-fever\#tab=tab_1.
Accessed 2021 June 12

8. Kerneis S, Kiovogui L, Magossouba $\mathrm{N}$ et al. Prevalencce and risk factors of Lassa seropositivity in inhabitants of forest region of Guinea: A crosssectional study. PLoS Negl Trop Dis $2009 ; \quad 3$ ( e 548 ) : https://doi.org/10.1371/journal.pntd. 0000548. Accessed 2021 Febraury 20.

9. Olise P. Viral Haemorrhagic fevers a nd the challenges of underdevelopment. Abuja: Ozega Publications 2016 [Accessed 2021 May 20].pp5-10

10. Federal Ministry of Health. Technical guidelines for Integrated disease surveillance and response. In: Control D, editor. Abuja: World Health Organisation; 2013. p. $1-400$ https://www.afro.who.int/publication s/technical-guidelines-integrateddisease-surveillance-and-responseafrican-region-third. Accessed 2021 April 23

11. World Health Organization. Lassa fever fact sheet No 179. Geneva: W $\mathrm{H} \mathrm{O}$; $\quad 2020$ https://www. who.int/healthtopics/lassa-fever\#tab=tab_ 1 . Accessed 2021 March 25

12. Usuwa IS, Akpa CO, Chuckwuma DU et al. Knowledge and risk perception towards Lassa fever infection among residents of affected communities in Ebonyi State, Nigeria: implications for risk communication. BMC Public Health $2020 ; \quad 20(217)$. https://doi.org/10.1186/s12889-0208299-3.

13. World Health Organization. Lassa Fever. Geneva: WHO 2018 ; https://www.who.int/en/newsroom/fact-sheets/detail/lassa-fever Accessed 2021 May 20.

14. Center for Disease Control and Prevention. Lassa fever. 2019; 
https://www.cdc.gov/vhf/lassa/index/ html (Accessed 2021 June 21.

15. Abraham C, Paschal S. The Health belief model. In: Mark C, Pual Norman, ed. Predicting and changing Health Behaviour. 3 ed. Cambridge: Cambridge University Press; 2015 https://www.researchgate.net/publica tion/232601319 Changing health $b$ ehavior Intervention and research with social cognition models [Accessed 2021 April 29]

16. Rosenstock IM, Strcher VJ, Becker MH. Social learning theory and health belief model. Health Educ Behaviour 1988; 15(2): 175-83.

17. Etsako West Local Government Area Edo State, Nigeria. Local Economic Empowerment And Development Strategy, (LEEDS). In: National Population Commision, editor. Ekpoma: National Population Commission,; 2008.p. 1-95

18. Edo State Ministry of Health. Updates on Lassa fever. In: Epidemiologist ES, editor. Lassa fever outbreak Edo State Ministry of Health; 2019

19. Araoye M O. Research Methodology With Statistics For Health and Social Sciences. 2nd ed. Ilorin: Nathadex
Puplishers; 2004

20. National Population Commission (Nigeria) and RTI international. 2015 Nigeria Educational Data Survey (NEDS) Education Profiel. Washinton DC: United Agency for International Development,;2016

https://shared.rti.org/content/2015nigeria-education-data-survey-nedseducation-profile Accessed 2021 May 25.

21. Odigie EA, Ighedosa SU, Vincent Osaghae $\mathrm{G}$ et al. Risk Perception of Lassa Fever and Rodent Control Practices in a University Campus in South-South Zone of Nigeria. NISEB Journal 2017; 17(1): 14-22.

22. Babalola S, Fatusi A. Determinants of use of maternal health services in Nigeria-looking beyond individual and household factors. $B M C$ pregnancy Childbirth 2009; 9(43).10.1186/1471-2393-9.

23. Bonner PC, Schmdt WP, Steven RB et al. Poor Housing Quality Increases Risk of Rodent Infestation and Lassa Fever in Refugee Camps of Sierra Leone. Am J Trop Med Hyg 2007; 77(1): 169-75. 